\title{
Water Cooled Concentrated Photovoltaic System
}

\author{
Mohan Kolhe ${ }^{\mathrm{a} *}$, Du Bin ${ }^{\mathrm{b}}$, and Eric $\mathrm{Hu}^{\mathrm{c}}$ \\ ${ }^{a}$ Faculty of Engineering \& Science, University of Agder, 4879 Grimstad, Norway \\ ${ }^{b}$ School of Energy and Environment, Southeast University, Nanjing, 210096, China \\ ${ }^{c}$ School of Mechanical Engineering, University of Adelaide, Adelaide, SA 5005, Australia
}

\begin{abstract}
Concentrated photovoltaic (CPV) system helps in focusing the direct solar radiation on the photovoltaic module. A CPV unit with water cooling system has been developed and manufactured at the School of Energy and Environment, Southeast University, China. It has been used for evaluating the performance of the CPV module with water cooling system for efficiency, power output and temperature. Also the effect of cooling water flow rate has been analyzed for performance evaluation of the CPV module. It has been found that the electrical output of the water cooled CPV is 4.7 to 5.2 times more than the PV module (without concentration and cooling). It has been noticed that the efficiency of the CPV mainly depends on the heat extraction rate and it helps in managing the cell temperature. And also the heat extraction rate from the CPV module mainly depends on the cooling water flow rate.
\end{abstract}

Keywords: Photovoltaic, concentrated photovoltaic system (CPV), water cooled CPV

\section{Introduction}

The transition to environmentally benign economy will reshape many features of today's society. Majority of the world population are away from the grid and do not have proper access to the electricity. Extending power lines from centralized sources to rural areas is often not yet economical, and so, decentralized power sources, such as the photovoltaic (PV) system, are a promising alternative [1]. Concentrated photovoltaic (CPV) system helps in focusing the direct solar radiation on the PV module. In $\mathrm{CPV}$, optical lenses are used to concentrate direct solar radiation on the PV module and hence the CPV module produces more output. But due to concentrated incident direct solar radiation on the PV module, the operating solar cell temperature also increases and therefore the solar cell efficiency decrease and the also the life time of the PV module decreases [2],[3]. It is important to include proper cooling system in the CPV system for increasing the efficiency of solar cell by reducing the operating cell temperature [4]. The Australian National University has developed a concentrating solar PV-thermal system by using the parabolic mirror and very encouraging results have been reported and they are: under typical operating conditions the thermal efficiency has been around 58\% and electrical efficiency around $11 \%$, therefore a combined efficiency of this system has been 69\% [5]. A CPV test unit with water-cooling system is developed and manufactured at the School of Energy and Environment, Southeast University, China. This system has been used for testing the PV module's performance for different parameters such as operating temperature, power output, and efficiency. In this work, its experimental performance analysis is presented.

\section{Developed CPV and Its Water Cooling System}

The developed CPV and its water cooling system are given in Fig. 1. In this system, the main shaft and

\footnotetext{
* Manuscript received June 14, 2012; revised August 8, 2012.

Corresponding author. Tel.: +47-3723 3293; E-mail address: mohan.l.kolhe@uia.no.
} 
the mounting rack are controlled through the sunlight sensors and two-axis sun-tracing is carried out for the CPV. A single-crystalline silicon PV module is used in this experimental analysis. This PV module is $1.08 \mathrm{~m}$ long and $0.14 \mathrm{~m}$ wide. The water cooling system is attached at the back of the PV module. The dimensions of the water cooling pies are: internal diameter of the pipe is $10 \mathrm{~mm}$, the external diameter is $13 \mathrm{~mm}$, distance between the incoming and outgoing pipes is $70 \mathrm{~mm}$, and a flexible conduit is used to connect the two pipes. Also a fixed PV module without solar concentration and cooling is used for comparing the performance of it with the CPV module. The E-type thermo-couples are used to measure the temperature of the solar cells. The ambient meteorological data have been measured by special meteorological data acquisition device. The cooling water is supplied through a pump and valve is used to control the cooling water flow rate. The PV module open circuit voltage, short circuit current, and the voltage and current at the maximum power point are measured with PVPM1000C solar cell tester, which is manufactured by the PV-Engineering GmbH Company, Germany.
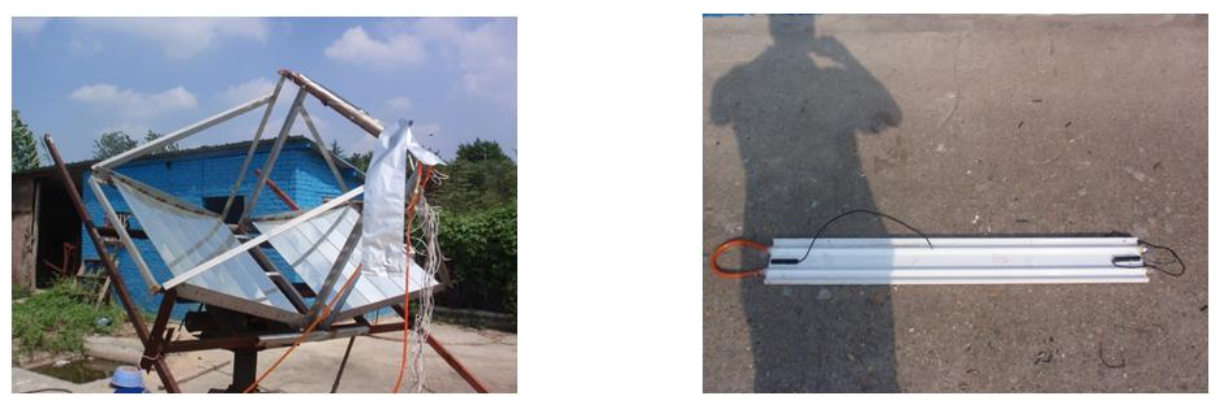

Fig. 1. Experimental set-up of water-cooled CPV module with water cooling pipes.

\section{Performance Analysis of the Developed CPV System}

The developed CPV module and water cooling system is used for analyzing the performance the PV module and it is compared with the fixed titled PV module (without concentration and cooling). The test day solar intensity is shown in Fig. 2 and the average wind speed on the test day was $0.25 \mathrm{~m} / \mathrm{s}$. The inlet temperature of the cooling water was $31{ }^{\circ} \mathrm{C}$. The CPV module's and fixed PV module's operating cell temperature are given in Fig. 3. During the test day, the maximum temperature difference between the CPV module and the fixed PV module was lower than $5{ }^{\circ} \mathrm{C}$. Compared with the fixed PV module, the CPV module receives more direct solar radiation. It transfers the heat to the cells and therefore the cell temperature increases. However, the experimental results have shown that the temperature difference between the CPV module and fixed PV module is not very much. The cooling water has extracted significant amount of heat which has been gained due to the temperature rise of the CPV module.

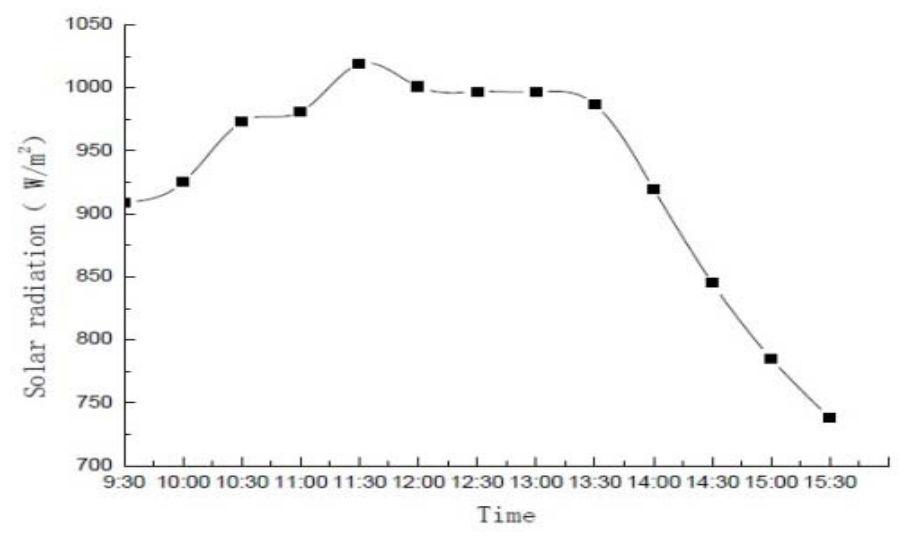

Fig. 2. Solar radiation on test day 


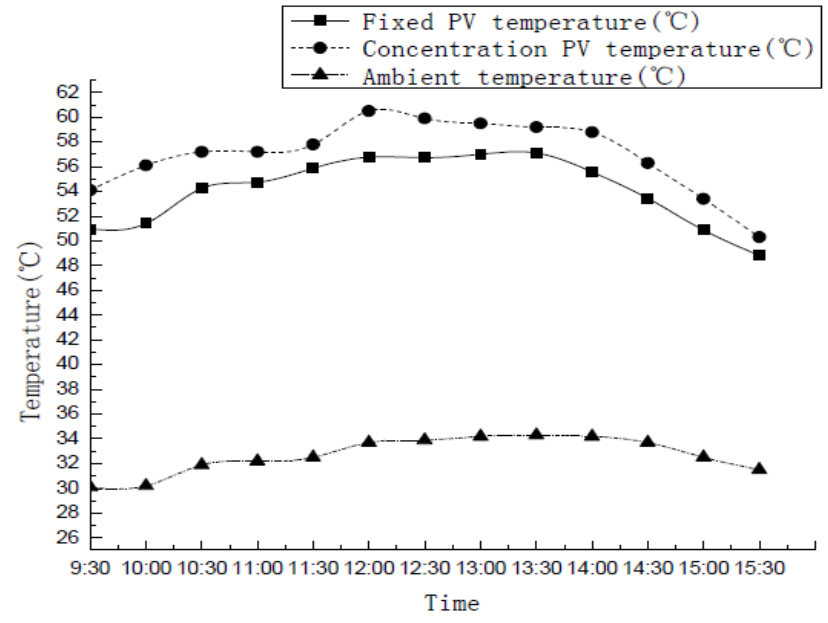

Fig. 3. CPV \& fixed PV modules operating cell temperature and ambient temperature on test day

In this experiment, the concentrating ratio of the concentration was 8.5. On the test day, the maximum produced electricity at solar noon from the CPV was $71.13 \mathrm{~W}$, and from the fixed PV module was 16.55 $\mathrm{W}$. It has been found that the output electricity of the CPV module was 4.7 to 5.2 times higher than the fixed PV module. The electrical output of the CPV and the fixed PV module is shown in Fig. 4. The solar radiation gain and output from the CPV can be increased significantly, but in this experiment, it was not achieved that much. The main reasons were the imperfection of concentrator geometry structure, the optical losses of the reflective mirrors and the efficiency drop due to the temperature rise of the solar cell. The solar cell output is in proportion to the cell short circuit current $[6,7]$ and therefore the short circuit current of the PV modules can be used to compare the incident solar radiation on the PV modules.

The variations of short circuit current of both modules are shown in Fig. 5 and it helps in analyzing the incident solar radiation on the CPV and fixed PV modules. The electrical efficiency, thermal efficiency of the CPV and the electrical efficiency of the fixed PV module are given in Fig.6. It has been observed that at solar noon, the efficiencies of both PV modules are reduced due to the higher cell temperature. At solar noon, the electrical efficiency of the CPV was $7.81 \%$ and of the fixed PV module was $10.68 \%$. It can also be observed by analyzing the Figs.3 and 6. In the CPV, as the incident solar radiation has increased, so the solar cell temperature has also increased and therefore the cooling water has extracted more heat from the CPV module. Hence the thermal efficiency of the CPV has increased till noon and gradually decreased after the solar noon. The variation in the solar cell temperature and the heat extraction rates mainly depends on the effective solar radiation. It has been observed that with increase in the cooling water flow rate, the electrical efficiency and the thermal efficiency increases rapidly.

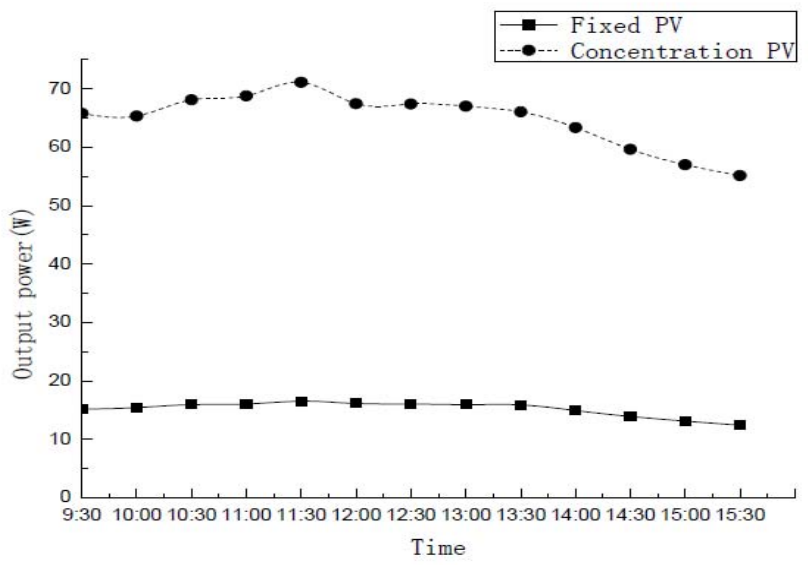

Fig. 4 CPV and fixed PV modules’ power output 


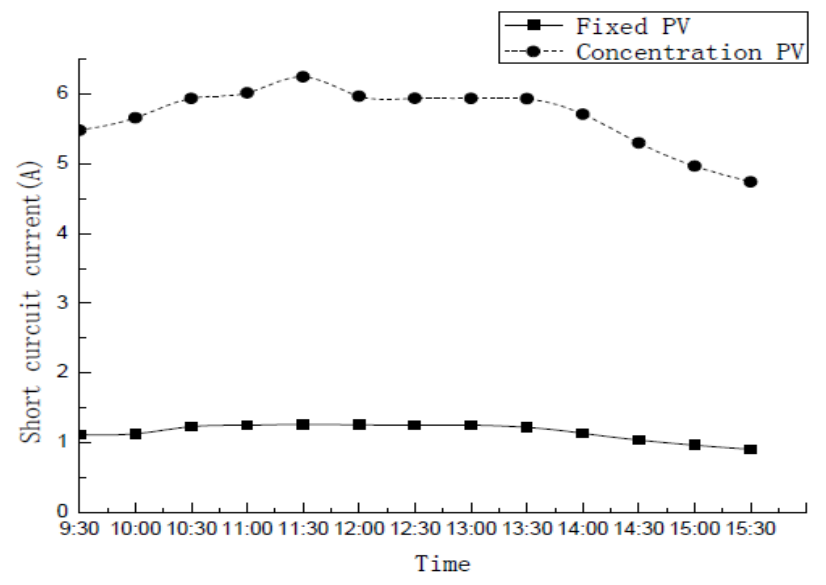

Fig. 5. Short-circuit current of PV modules

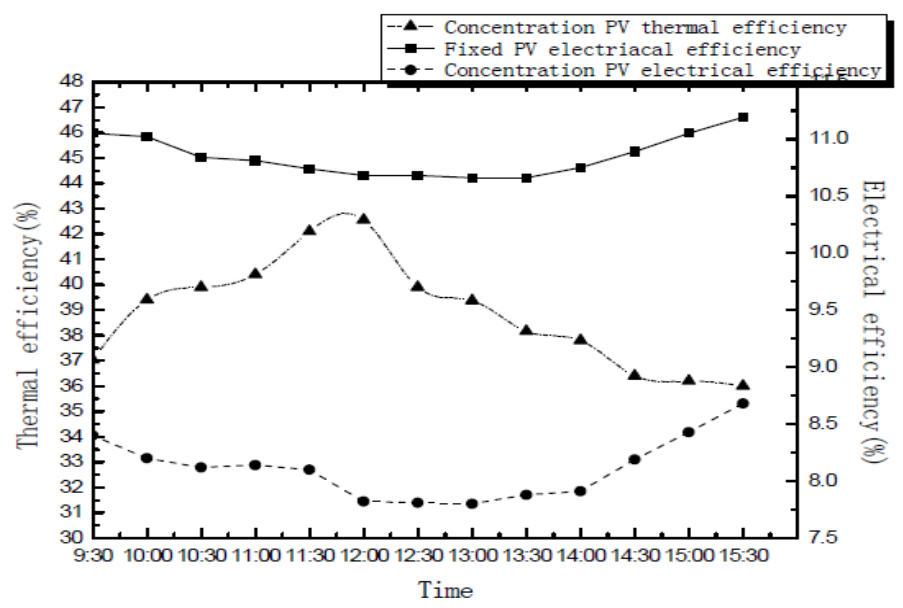

Fig. 6. CPV and fixed PV modules' electrical efficiency and thermal efficiency of CPV

\section{Conclusion}

This work reports the experimental performance analysis of a water-cooled CPV module. It has been observed that the output from the CPV with cooling is much more than that from the fixed PV module. It has been found that the output electricity of the CPV module is 4.7 to 5.2 times higher than that from the fixed PV module. Based on the obtained experimental results, the output electricity of the CPV module was around 4.9 times higher than the fixed PV module (on test day), but its electrical efficiency was lower than $9 \%$ at most of the time. The main reasons behind this were the imperfection of concentrator geometry structure, the optical losses of the reflective mirrors, non-uniform illumination levels on the PV module and the drop in efficiency due to the temperature rise of the solar cell. With the increased water flow rate, more heat can be extracted from the CPV module and it can help in reducing the cell temperature and hence in increasing the cell electrical efficiency.

\section{Acknowledgements}

Dr Du Bin is very much thankful to the School of Energy and Environment, Southeast University, Nanjing, 210096, China for providing the facility and permitting for publishing the experimental results of this research work and also giving financial support for doing post-doctoral research work at the University of Adelaide, Australia. Also Bin is very grateful to the School of Mechanical Engineering, University of Adelaide for hosting him as a post-doctoral researcher. 


\section{References}

[1] Kolhe M. Techno-economic optimum sizing of a stand-alone solar photovoltaic system. IEEE Trans. on Energy Conversion, 2009; 24(2):511-519.

[2] Royne A, Dey CJ, Mills DR. Cooling of photovoltaic cells under concentrated illumination: a critical review. Solar Energy Materials \& Solar Cells, 2005; 86(4):451-483.

[3] Sonneveld PJ, Swinkels GLAM, van Tuijl BAJ, Janssen HJJ, Campen J, Bot GPA, Performance of a concentrated photovoltaic energy system with static linear Fresnel lenses. Solar Energy, 2011; 85(3):432-442.

[4] Wang YN, Lin TT, Leong JC, Hsu YT, Yeh CP, Lee PH, Tsai CH. Numerical investigation of high-concentration photovoltaic module heat dissipation. Renewable Energy, 2013; 50:20-26.

[5] Coventry JS. Performance of a concentrating photovoltaic/thermal solar collector. Solar Energy, 2005; 78(2): 211-222.

[6] Kolhe M, Kolhe S, Joshi JC. Determination of daily volume of pumped water as a function of mechanical energy from a photovoltaic water-pumping system. Proceeding of Institution of Mechanical Engineers, Part A: Journal of Power and Energy, 2001; 215(A3):399-402.

[7] Kolhe M, Joshi JC, Performance analysis of directly coupled photovoltaic electro-mechanical systems. Proceedings of the Institution of Mechanical Engineers, Part A: Journal of Power and Energy, 2002; 216(6):453-464. 